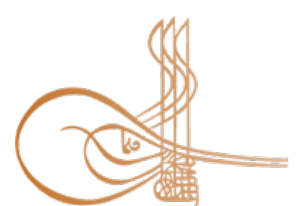

www.turkishstudies.net/economy

Turkish Studies - Economics, Finance, Politics

eISSN: $2667-5625$

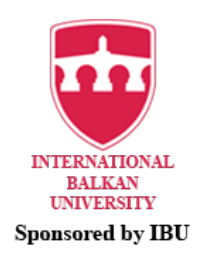

Research Article / Araştırma Makalesi

\title{
ABD'nin Yeni Çevreleme Konsepti: Kosova Örneği
}

\author{
USA's New Containment Policy: Kosovo Case
}

\author{
Fatih Fuat Tuncer*
}

\begin{abstract}
After Kosovo's one-sided declaration of independence, many new argumentations came to the agenda and the 'Kosovo Issue' occurred a new polarization in international system in 21. Century. While the USA, as the winning side of the Cold War, was supporting Kosovo's independence; Russia ---as the other superpower of the Cold War and the successor of Soviet Union- openly objects Kosovo's independence. This situation has created a new competition among the United States who is believed to gain a permanent victory in the Cold War and Russia who desires to replace its status as a superpower. This new competition was first truly tested in Kosovo. Following the dissolving of Yugoslavia, the political map of Balkans was reshaped. The positions taken by the countries that have declared independence from Yugoslavia have revitalized the discussion of power in the international system. War in Yugoslavia, in a way, have shown that end of history has not yet arrived and international system is bound to see important crises in the future. Especially the experiences in Bosnia-Herzegovia and Kosovo have not limited only with regional impact but became effective in global level wherein actors multiplied with globalization following the Cold War. Russia's reaction to the Yugoslavian War and the USA's intervention in the problem through the NATO have illustrated a new dimention of USA-Russia competition. Russia's assumption that it was contained by the USA after the Cold War has emerged 'a new containment concept' in the field of international relations.
\end{abstract}

Structured Abstract: Following the end of Cold War, the transatlantic alliance was drifted into a new discussion regarding 'the future of new era'. Indeed, the main argument started before the end of Cold War. Especially, liberals objected to the view which formulated the bipolar system in international relations as 'insecurity' and 'being more powerful'. Against the criticisms that system has been blocked, realists work for the future of realism and tried to update the theory according to the daily requirements. Especially at this point, Waltz's book in 1979 'International Political Theory' reformulated realizm and caused the emergence of 'neorealizm' discussions. Waltz, by considering that nation states are not the only actor in international system, set the base of a new approach. In this new approach, while he does not deny nation state's primary role in international system entirely, he underscores that the structure of international system is equally important.

Containment policy is a doctrine which was created by the USA as being the winner side of the Second World War to limit the increasing global impact of the Soviet Union, especially in the Eastern Europe (Özcan, 2019: 1). It is known that, during the war, the decision makers in the USA did not intend to limit and control

\footnotetext{
* Dr. Öğretim Üyesi, İstanbul Gelişim Üniversitesi, İktisadi İdari Bilimler Fakültesi, Siyaset Bilimi ve Uluslararası İlişkiler Bölümü

Asst. Prof. Dr., Istanbul Gelisim University, Faculty of Economics, Administrative and Social Sciences, Department of Political Science and International Relations

ORCID 0000-0002-4034-5949

fftuncer@gelisim.edu.tr
}

Cite as/ Atıf: Tuncer, F. F. (2020). ABD'nin yeni çevreleme konsepti: Kosova örneği. Turkish Studies - Economy, 15(2), 975-985. https://dx.doi.org/10.29228/TurkishStudies.42831

Received/Geliş: 10 April/Nisan 2020

Accepted/Kabul: 20 June/Haziran 2020

Copyright $($ INTAC LTD, Turkey 
the Soviets. Indeed, they demanded to return back to its own continent and to be free from the problems of the old continent. At this point, it appears that it was the Soviets which started the era known as the Cold War. The Soviet resistance against retreating back from the Europe and its efforts for building puppet governments there became effective on the sudden changes of the USA's post-war policies. Especially Churchill's warnings about the Soviets on behalf of England became true. Churchill assumed that the Soviets entered into a new concept by putting an iron curtain over the Eastern Europe, and launched the Cold War. Churchill said the Soviets would target English National Communities and the USA. As a response to Stalin's uncompromising stance, USA prepared a new strategy which lasted for half a century by relying on George Kennan's report in 1946. As a result of this so-called strategy the 'containment policy', the Cold War started. Kennan emphasised that the conflict will not be based on military force but ideology and the most important thing will not be USA's power but its patience.

With the dissolve of the Soviet Union, the Cold War ended and two basic discussions started in the discipline of international relations: 'the end of history' and 'clash of civilizations'. Political scientist Francis Fukuyama said with the Cold War, the history was ended because the USA removed the last obstacle against liberal democracy and free market economy. According to Fukuyama, now peace and democracy will rule the world. By opposing this idea, American strategist Samuel Huntington offered the fighting sides will be civilizations after the Cold War. According to Huntington, the new war will start between the West and the East, the North and the South, Islam and Christianity. Huntington's this thesis took a lot of attention and became inspiring for the subsequent studies. Huntington's classification as West culture is good and the East culture is bad received criticisms particularly from the authors who do not define themselves as 'hegemonic westernist'. Current developments, on the other hand, is defined by realists such as Kenneth N. Waltz as the restoration of order. While considering state as the main actor and opening a new space to other actors with globalisation, new-realism considers power struggle and competition are main determinants in international system. The discussions regarding the future of new power balance in international system after the Cold War have not ended yet. The assumption of nation state will come to an end by globalisation has been tested many times. First, Yugoslavia's transformation to a new nation state, then 2008 economic crisis and current corona virus epidemic have shown that the unique actor in international system is nation state. It is still utopic that a global compromise may replace anarchy in current international system. If a general evaluation of this work has been made, over the Kosovo case, it is considered that the USA adopted a new containment policy, power struggle and a competition concept against Russia. Again the Kosovo Crisis is a good example that the USA's containment policy during the Cold War also continues after the Cold War.

With reference to Waltz's words, this work will investigate the assumption that the USA entered in a new containment policy against Russia as well as power struggle and a competition concept. The purpose of the work is to investigate whether the USA's containment policy after the Cold War against its rivals is permanent or not. While neo-realism builds the theoretical framework of the work, the work is limited with the Kosovo case. The work has two main sections; the first section will argue 'new containment concept' and the second section will analyse 'USA approach to the Kosovo case' by relying on this new concept.

Keywords: The Problem of Kosovo, New Containment Policy, Neorealism, NATO, Yugoslavia, Regional Studies, International Politics

Öz: Kosova'nın 2008 yılında tek taraflı bağımsızlık ilanın ardından birçok yeni tartışma gündeme gelmiş ve 'Kosova Sorunu', 21. Yüzyıl'da uluslararası sistemde yeni bir kutuplaşmayı ortaya çıkarmıştır. Soğuk Savaş'ın kazananı ABD, net bir şekilde Kosova'nın bağımsızlığını desteklerken, Soğuk Savaş'ın bir diğer süper gücü Sovyetler Birliği'nin ardılı ve varisi Rusya da Kosova'nın bağımsızlığına net bir şekilde karşı çıkmıştır. Bu durum, Vladimir Putin sonrası toparlanan ve yeniden süper güç olarak dünya sahnesine geri dönmek isteyen Rusya ile Soğuk Savaş'tan kesin bir zafer ile çıktığına inanılan ABD arasında yeni bir rekabetin oluştuğu iddiasını ortaya çıkarmıştır. Bu yeni rekabetin ilk ve ciddi sınavı ise Kosova'da verilmiştir. Yugoslavya'nın dağılması ile Balkanların siyasi haritası yeniden şekillenmiştir. Yugoslavya sonrası bağımsız olan yeni ülkelerin aldıkları pozisyonlar uluslararası sistemdeki güç tartışmasını yeniden canlanmıştır. Yugoslavya savaşı bir anlamda Tarihin Sonu'nun gelmediğini göstermiş ve uluslararası sistemin soğuk savaş sonrası da önemli krizlere gebe olduğunu ispatlamıştır. Özellikle Bosna-Hersek ve Kosova'da yaşananlar yalnızca bölgesel etki alanıyla sınırlı kalmamış ve Soğuk Savaş sonrası küreselleşme ile birlikte aktörlerin de çoğaldığı küresel düzeyde de etkili olmuştur. Yugoslavya Savaşı'na Rusya'nın gösterdiği reaksiyon ve ABD'nin soruna 
NATO aracılılığı ile müdahalesi, ABD ve Rusya arasındaki rekabetin yeni bir boyutunu ortaya koymaktadır. Rusya'nın Soğuk Savaş sonrası ABD tarafından yeniden çevrelendiğini iddia etmesi ise uluslararası ilişkiler alanında 'yeni çevreleme konsepti' tartışmasını ortaya çıkarmıştır.

Anahtar Kelimeler: Kosova Sorunu, Yeni Çevreleme Konsepti, NATO, Neo-realizm, Yugoslavya, Bölgesel Çalışmalar, Uluslararası Siyaset

\section{Giriş}

Soğuk Savaş sonrası bütün dünyada yaşanan değişim ve dönüşüm, Balkanları da derinden etkilemiş̧ir. Soğuk Savaş dönemi boyunca 'Batı dışı' olarak konumlanan ülkelerdeki rejimler, Berlin Duvarı'nın yıkılması ile birer birer çökmüștür. Romanya' da Çavuşesku dönemi, Arnavutluk'ta Enver Hoca dönemi ve Bulgaristan'da Jivkov dönemleri sona ererken, Tito'nun ölümü sonrasında Yugoslavya'da başlayan siyasi kriz iç savaşa dönüşmüş ve Yugoslavya'daki cumhuriyetler 1974 Anayasası'ndaki 'self determinasyon' hakkına dayanarak bağımsızlıklarını ilan etmişlerdir. 1974 Anayasası ile cumhuriyetler Yugoslavya Federasyonu'nun kurucu unsurları sayılırken Kosova ve Voyvodina özerk bölgeleri kurulmuştur. Kosova, bu yeni statüsünde cumhuriyetler gibi kurucu unsur sayılmasa da Kosova özel bir kimlik kazanmış, yasama ve yürütme erkelerine sahip olurken Yugoslavya federasyonları organlarında eşit temsil ve oy hakkı kazanmıştı (The Secretariat of The Federal Assembly Information Service, 1974). 1974 anayasasına göre federasyondan ayrılma hakk1 bulunmayan Kosova'nın bu statüsü Yugoslavya Savaşı süresince ve sonrasında tartışma konusu olmuştur. Özellikle ABD ve Rusya arasında rekabetin yeniden başlamasının da bir anlamda sembolü olan Kosova, 2008 yılında bağımsızlığını ilan ederek, bağımsızlığını tanıyan ve tanımayan ülkeleri yeni bir tartışmanın içerisine çekmiştir.

Çevreleme politikası, II. Dünya Savaşı'ndan zaferle ayrılan ABD tarafından zaferin diğer ortağı SSCB'nin başta Doğu Avrupa'da olmak üzere dünyada giderek artan etkisini sinırlamak için oluşturulan doktrindir (Özcan, 2019). Savaş döneminde ABD'deki karar alıcıların Sovyetleri savaş sonrasında sınırlamak ve kontrol altında tutmak gibi bir niyetlerinin olmadığı bilinmektedir. Yeniden kendi kıtasına dönmek ve eski dünyanın sorunlarından uzak durmak isteyen ABD'yi bu duruma getiren ve dünya tarihinde Soğuk Savaş olarak anılacak dönemi başlatanın bir anlamda Sovyetler Birliği olduğu görülmektedir. Sovyetlerin Avrupa'dan geri çekilmekte direnmesi ve orada kukla yönetimler inşa etmesi ABD'nin, savaş sonrası politikasının ani değişiminde etkili olmuştur. Özellikle İngiltere adına konuşan Winston Churchill'in Sovyetler konusunda ABD'ye verdiği uyarıların haklı çıktı̆̆ görülmektedir. Zira Churchill, Sovyetlerin Doğu Avrupa'ya bir demir perde indirerek yeni bir konsepte geçtiğini, Soğuk Savaş'ın başladığını vurguluyor ve Sovyetlerin İngiliz Milletler Topluluğu ve ABD'yi hedef alacağını söylüyordu (Hook \& Spainer, 2016). Stalin'in uzlaşmaz tutumu üzerine ABD, yeni bir strateji arayışına girmiş ve George Kennan'ın 1946 yılında hazırladığı rapora dayanarak yaklaşık yarım asır sürecek bir karşı strateji planlanmıştır. 'Çevreleme Doktrini' olarak tarihe geçecek olan bu strateji neticesinde de Soğuk Savaş başlamıştır. Kennan, bu planda mücadelenin askeri değil ideolojik olarak olacağı ve önemli olanın ABD’nin gücü değil, sabır ve dirayeti olduğunu vurgulamıştır (Kissenger, 2011).

Sovyetler Birliği’nin dağılması ile Soğuk Savaş sona ermiş ve uluslararası ilişkiler disiplini içerisinde iki temel tartışma başlamıştır: 'tarihin sonu' ve 'medeniyetler çatışması'. Siyaset Bilimci Francis Fukuyama, Soğuk Savaş ile birlikte bir anlamda tarihin sonunun geldiğini, ABD'nin bu savaştan galip çıkarak liberal demokrasi ve serbest piyasa ekonomisi önündeki son engeli kaldırdığını söylemiştir. Fukuyama'ya göre dünyaya artık barış ve demokrasi hâkim olacaktır (Fukuyama, 1989). Durumun böyle olmadığını savunan ve yeni bir mücadelenin başlayacağını öngören Amerikalı Stratejist Samuel Huntington ise Soğuk Savaş sonrasında savaşanların medeniyetler olacağını söylemiştir. Huntington'a göre Batı ve Doğu, Kuzey ve Güney, İslam ve Hristiyanlık savaşı başlayacaktır (Huntington, 1996). Huntington'un bu tezi büyük ilgi uyandırmış ve Soğuk Savaş sonrası uluslararası ilişkiler disiplini içerisinde birçok çalışmaya konu olmuştur. 
Hungtinton'un çalışmasında 'iyi’ olarak Batı kültürünü, 'kötü’ olarak da Doğu kültürünü işaret etmesi özellikle kendilerini 'hegemon Batılı' olarak adlandırmayan aydınlar tarafından büyük tepki görmüştür (Fox, 2005). Bugün yaşananlar ise Kenneth N. Waltz başta olmak üzere realistlere göre düzenin yeniden dengeye oturmasıdır. Neo-realizm devleti esas aktör olarak tanırken, küreselleşme ile birlikte önemi artan diğer uluslararası aktörlere de alan açarken, güç mücadelesinin ve rekabetin uluslarası sistemde temel belirleyeci olduğunu savunmaktadır (Waltz, 2015).

$\mathrm{Bu}$ çalışma ise Waltz'ın söylediklerinden hareketle, Kosova sorunu örneği üzerinden ABD’nin Rusya'ya karşı yeni bir çevreleme politikası ile güç mücadelesi ve rekabet konseptine giriştiği savını inceleyecektir. Çalışmanın amacı Soğuk Savaş'tan itibaren ABD'nin kendisine rakip gördüğü güçleri çevreleme politikasına tabi tutan ABD'nin bu politikasının Soğuk Savaş sonrası süreklilik taşıyıp taşımadı̆̆ının incelenmesidir. Çalışmanın kuramsal alt yapısını neo-realizim yaklaşımı oluştururken, çalışma Kosova örneği kapsamında sınırlandırılmıştır. Çalışma iki ana bölümden oluşacak olup; ilk bölümde 'yeni çevreleme konsepti' tartışması ele alınırken, ikinci bölümde de 'ABD’nin Kosova sorununa yaklaşımı' bu yeni konsept üzerinden analiz edilecektir.

\section{Neorealizm Kapsamında Yeni Çevreleme Konseptinin İnşaası}

Soğuk Savaş'ın sona ermesi ile birlikte Transatlantik ittifakı 'yeni dönemin nasıl olacağı' üzerine bir tartışmanın içerisine sürüklenmiştir. Aslında temel tartışmanın Soğuk Savaş sona ermeden başladığı görülmektedir. Özellikle Soğuk Savaş döneminde ortaya çıkan iki kutuplu yapıya dayanan uluslararası ortamdaki ilişkilerin 'güvensizlik' ve 'daha güçlü olmak' üzere formüle edilmesine liberalist kuramcılar eleştiri ile yaklaşmıştır. Sistemin tıkandığı ve ilerleyemediği eleştirilerine karşı realistler, realizmin geleceği üzerine çalışmış ve teoriyi günün gereklerine göre güncellemek istemişlerdir. Özellikle bu noktada 1979 'da Waltz'un yazmış olduğu 'Uluslararası Politika Teorisi' kitabı bir anlamda realizmi yeniden formüle ederek 'neo realizm' yaklaşımı tartışmalarının ortaya çıkmasına neden olmuştır. Waltz, özellikle liberallerin uluslararası sistemde tek aktörün ulus devletler olmadığı iddiasını göz önüne alarak, yeni bir yaklaşımın temellerini atmıştır. Bu yeni yaklaşımda Waltz, ulus devletin uluslararası sistemdeki ‘biricik' rolünü tam anlamı ile red etmezken, uluslararası sistemin yapısının da en az ulus devletler kadar önemli olduğunun altını çizer. Waltz, uluslararası sistemin yapısını yorumlarken üç temel yaklaşım üzerinden ilerler (Waltz, 2015):

- Uluslararası sistem red edilemez bir şekilde anarşik yapıdır ve ulus devletlerin asıl amacı bu anarşik ortamda var olabilmektir.

- Uluslararası sistemin temel ve en güçlü aktörleri ulus devletlerdir. Uluslararası ve ulusüstü örgütlerde de önemli olan devletlerin çıkarlarıdır.

- Uluslararası sistemde, her devletin farklı özellikleri olsa da sistem içerisinde her ulus devlet eşittir; ancak her devletin kapasitesi farklıdır.

Waltz'un sisteme bakışı, diğer klasik realistlerden farklıdır. Hobbes'a dayanan klasik realizmden Waltz'un neo-realizminin farkı temelde uluslararası sisteme yorumlamakta yatmaktadır. Hobbes'un 'korku' ve 'hayatta kalma' üzerinden formüle ettiği ve Leviathan'da cisimleştirdiği devlet, tektir, biriciktir ve en güçlü olmak zorundadır (Hobbes, 2019). Bu bakış, devletin uluslararası sistemde her halükarda kendi çıkarı için hareket edeceğinin bir ilanıdır. Waltz ise sadece ulus devlete odaklanmaktansa biraz da uluslararası yapıyı incelemeyi tercih etmektedir. Waltz'a göre yine 'hiyerarşis' ve 'anarşi' temel siyasal belirleyici kavramlardır (Donnely, 2012). Jack Donnely bu iki ülke üzerinden Waltz'ın ortaya attı̆ğ yeni önermeyi şu şekilde yorumlar:

"Yerleşik, uzlaşılmış kuralların geçerli olduğu bir ortamda yürütülen siyasetle anarşik bir ortamda yapılan siyaset arasında' çok belirgin farklar vardır... Waltz; anarşinin birimler arasındaki işlevsel farklılaşmayı büyük ölçüde ortadan kaldırdığını iddia eder. Anarşik/uluslararası düzenlerde her bir birim, 'kendi başının çaresine bakabilecek bir konuma sahip olmak zorundadır, çünkü bunu 
yerine getirebilecek başka hiç kimse bulunmaz. Devletler arasindaki farklar, 'işlev' değil, güç ve yeteneklerle ilgilidir. 'Ulusal siyaset', belirli özel ișlevleri yerine getiren farklllaşmış birimlerden oluşur. 'Uluslararası siyaset' birbirinin etkinlik ve davranışlartnı taklit eden benzer birimlerden meydana gelir." (Donnely, 2012).

Donnely, Waltz'un da üzerinde durduğu 'ulusal siyaset' ve 'uluslararası siyaset' ayrımına dikkat çeker. Waltz'un dediği gibi anarşi birimler arasındaki işlevsel farkları büyük öçlüde ortadan kaldırmıştır. Ancak, güç ve yetenek hala devletler arasındaki temel farkı oluşturmaktadır. Bunun uluslararası sisteme yansımasının yorumu da bir anlamda neo-realistleri realistlerden ayırmaktadır. Mustafa Aydın(2004), bu durumu şu şekilde açıklamaktadır:

"Genel olarak, bir taraftan uluslararasl politikanm değişmediğini, yüzylllardır benzer kalıplar çerçevesinde hareket edildiğini söylerken (yani bireylere gidişatı değiş̧tirme konusunda fazla bir insiyatif tanimazken), diger taraftan devlet adamlarının en temelde 'devletin bekasinin sağlanması' olarak tanımlanan ulusal çıkar peşinde koşmaları 'gerektiğini' söylemek açıkça normatif bir ifade tarzıdır. Fakat, bu noktada klasik realizmle çağdaș (neo)realist modeller arasında önemli bir farklılık vardır. Klasik realizm, Uluslararası İlişkilerin 1960'larda davranışsalcı eleştirilerinden etkilenmesinden önce egemen olan yaklaşımlardan biridir. Antik Yunan'dan bugüne kadar çok farklı tarih dönemlerinde yaşamış olan klasik realistier temel yaklaşımlarında normatif olup, ulusal guvenlik ve devlet bekası gibi siyasal degerlere odaklanmışlardı. Realizmin davranışsalcılı̆gn etkisiyle evrimleşen çagdaş (neo) versiyonları ise temelde davranısssalcıllk sonrası 'bilimsel' metodolojiyi kullanarak uluslararası sistem ve yapıya odaklanarak normativizmden uzaklaşılrlar." (Aydin, 2004)

Klasik realistler uluslararası siyaseti, rekabet, savaş, çatışmanın sürekli tekrarlandığı bir arena olarak yorumlarken, neorealistler bu yorumu tam anlamı ile red etmemekle birlikte realist varsayımları yeni uluslararası yapıya odaklanarak test etme eğilimindedir. Waltz bu tekrarlanma durumunu anarşik durumun hiyerarşik bir biçim alana kadar devam edeceğini şu şekilde ifade eder:

"Uluslararast ilişkilerde, kaliplar tekrarlaniyor, temalar değişmezlik gösteriyor ve olaylar kendilerini sonsuz şekillerde tekrarlayı duruyor Uluslararası olaylar nadiren biçimsel ya da niteliksel değişiklik gösterirler. Bunun yerine, bir ısrar gösterirler ve bu anarşik uluslararası alan, hiyerarşik bir biçim alincaya dek sürer." (Waltz, 2015).

George Kennan tarafindan planlanan 'çevreleme doktrini' de, Liberal ABD'nin, uluslararası sistemde 'tehditkâr' Sovyetleri bir anlamda taklit etmesidir. Yani, Sovyetlerin yayılmacılığına karşı, onu çevreleyerek dünyaya yayılmak ve uluslararası sitemde kendi bekasını korumak amacını taşıyan bir ABD'nin ortaya çıkmasıdır. 12 Mart 1947'de ABD Başkanı Harry Truman'nın Kongre'de yaptığı konuşma ile çevreleme politikası resmiyete geçmiş ve Truman Doktrini olarak anılacak yeni ABD politikası ile Soğuk Savaş, ABD açısından başlamıştır. Marshall yardımları ile Avrupa'yı Sovyetlere karşı yeniden toparlamayı hedefleyen ABD, bu kapsamda tam 13 Milyar ABD Doları bütçe ayırmış ve Avrupa'daki ülkelere dağıtmıştır (U.S Embassy Ankara, 2007). 4 Nisan 1949'da da NATO'nun kurulması ile de ABD, Soğuk Savaş'ın askeri cephesini de açmış oluyordu. Bu karşılıklı kutuplaşma politikası tam yarım asır sürecek ve bu kutuplaşmadan ABD, Kennan'ın da dediği gibi 'uzun dönemli, sabırlı, ancak kati ve dikkatli bir çevreleme politikası' ile zaferle çıkmıştır (The Guardian, 2005). Hook ve Spanier, bu dönemi şu şekilde anlatır:

"ABD Avrupa ile yetinmeyecekti. Komünizmi çevrelemek için başka yerlerle de aktif bir şekilde meşgul olması gerekecekti. 1940'ların sonu ve 1950'lerin başında, Sovyetler Birliği'nin Asya çeperi ve Çin, Amerikan çevrelemesinin ikinci hedefi oldu. Batı Avrupanin aksine, Asya devletlerinden birçoğu sömürgecilikten yeni çıkmıştı; milliyetçilik ve Batı karşıtı duyguları yoğundu. Özellikle 1949'da komünist bir Çin yönetiminin başa geçmesi, Asya'daki Amerikan pozisyonunu zayıflattı. Ondan sonra, $A B D$, biri dünyanın en geniş toprağına(Sovyetler Birliği), diğeri (Çin) dünyanın en büyük nüfuzuna sahip, askeri olarak güçlü iki komünist devlete karşl durdu. George Kennan'ın uyardı̆̆ı gibi Soğuk Savaş’ın kapsamı geniş, süresi uzun olacaktı.” (Hook \& Spanier, 2016). 
Kennan'ın çizdiği çerçeve ABD tarafından kimi zaman sertçe kimi zaman da daha yumuşak tonlarla uygulanmış ancak kesinlikle Komünizmin çevrelenmesinden vazgeçilmemişti. Netecide Berlin Duvarı'nın yıkılması ve S.S.C.B'nin dağılması ile Soğuk Savaş sona ermiş ve ABD'nin itibarı yükselmişti. Çoğu yazara göre dünya, barış ve bireysel özgürlük dönemine giriyordu. Hatta Fukuyama daha da ileri giderek, "Şahit olduğumuz şey sadece Soğuk Savaş'ın sonu veya tarihin belli bir döneminin geçişi değil, tarihin kendisinin sonu, yani insanoğlunun ideolojik evriminin son noktası ve Batı liberal demokrasisinin insan yönetimindeki nihai form olarak evresenleşmesidir" diyecekti (Fukuyama, 1989). Ancak, Fukuyama'nın geldiğini söylediği tarihin sonu gelmeyecekti. Ortadoğu ve Balkanlarda başlayan çatışmalar ve bölünmeler, iki kutuplu olmayan bir dünyada dengenin kaybolduğunu ve güç boşluğunu yeni aktörlerin doldurmak istediği tartışmalarını ortaya çıkaracaktı. Rusya'nın yeniden uluslararası yapıda dengeye sağlaması ve ABD'yi dengeleyen güç olarak sahneye dönüşü ise Putin'in 1999 yılında Yeltsin'in istifası ile Rusya'nın dümenine geçmesi ile başlamıştır. Bundan sonraki süreç ABD için yeni bir çevrelemenin hayata geçmesi olmuştur. Önce, Kosova sonrasında Kafkasya'daki 'renkli devrim' denemeleri ve son olarak da Arap Bahar1 ile birlikte başlayan Suriye Krizi bu yeni çevrelemenin boyut değiştirmiş hali olarak değerlendirilebilecektir.

\section{ABD'nin Kosova Sorunu'na Yaklaşımı}

Yugoslavya'daki iç savaş, ABD için yeni dönemin en önemli gelişmesi idi. Artık sahnede tek süpergüç olarak kalan ABD, Yugoslavya'daki savaşta en ciddi sınavını verdi. Sovyetlerin yokluğunda dünyanın her yerinde yeni aktörler ve yeni tehditler ortaya çıkıyordu. Saddam'ın Kuveyt denemesi ve Miloseviç'in Yugoslavyası'nda yaşananlar, ABD'nin yeni dönemdeki en ciddi sınavları idi. Bir geçiş döneminde olan Yeltsin'in Rusya'sı, ABD'ye karşı 1lımlı davranmış ve ABD'yi tek güç olarak bu sorunlarda çözüme zorlamıştı. Ancak, her iki sorun da ABD için tam anlamı ile bir zaferi getirmedi. Saddam'ın Irak'taki varlı̆̆ını sürdürmesi ve Bosna'daki Dayton Anlaşması sadece var olan sorunu dondurmak anlamında idi. Bosna Hersek'teki trajediyi bir şekilde atlatan ABD'nin en ciddi sınavı ise Kosova'da oldu. Zira Yugoslavya'daki savaş Bosna'da sonlanmamış ve Kosova' da yeni bir cephe açılmıştı. Kosova, Yugoslavya'nın en fakir ve en küçük parçası olmasına rağmen Sırp Milliyetçiliği için sembolik bir öneme sahipti. 1389 Kosova Savaşı miti Sırplar için oldukça önemli olduğu kadar, Miloseviç’in siyasi kariyeri için de önemli idi. Zira Miloseviç, Yugoslavya yönetimini ele geçirir geçirmez Yugoslavya'yı nasıl bir gelecek beklediğinin sinyallerini savaşın 600. Yılı sebebi ile burada yaptığı bir konuşmada vermişti. Miloseviç, iktidara gelir gelmez 1974 Anayasa'sının Kosova'ya verdiği tüm hakları gasp ederek geri almıştı. UÇK(Kosova Kurtuluş Ordusu) çatısı altında silahlanan Arnavutların mücadelesi Belgrad tarafından sert bir şekilde bastırılsa da hareket sona ermemişti (Vrkic, 2015). Miloseviç, Slovenya, Hırvatistan ve Bosna'da yaşadığı mağlubiyetin acısını çıkartmak ve en azından bir zafer kazanabilmek için Kosova'da eşi benzeri görülmemiş bir şiddet dalgasını başlattı. UÇK'nın da sert karşılık vermesi ile bütün Balkanları etkileyecek yeni bir savaşın başlama ihtimaline karşı ABD ve Avrupalı devletler, Kosovalı Arnavutları ve Belgrad'1, Fransa'da Rambouillet'te bir araya getirdiler. ABD, masadan yeni bir Dayton çıkmasını ve savaşın sona ermesini umuyordu. Ama Miloseviç, Kosova'yı bağımsız yapmayan ancak Kosova'ya bağımsızlıktan az özerklikten fazlasını veren bu anlaşmayı kabul etmedi (Herring, 2000). ABD'nin de NATO aracıllğı ile Kosova'ya müdahele etmekten başka çaresi kalmamıştı 1999 Şubat'ındaki Rambouillet görüşmesinde masayı dağıtan Miloseviç'e, 1999 Mart'inda NATO çok sert bir cevap verdi.

Soğuk Savaş sonrası gerçekleşen bu NATO operasyonu ile Balkanlardaki son raundu ABD kazanacaktı. Yeltsin'in Rusya'nın iç sorunları sebebi ile soruna müdahil olamaması ve NATO operasyonuna caydırıcı bir şekilde karşı çıkamaması Rus-Sırp ittifakını zedelemiştir. Ancak bu operasyon Kosova sorununu ve Miloseviç yönetimini tam anlamı ile bitirememiştir. Bu durumu Hook ve Spainer şu şekilde aktarır: 
“...NATO’nun zaferi kısmi ve son derece kisitllydl. Kosova ‘özgürleştirilmişti’, ama -en azından ismen- Yugoslavya'nın bir parçası olarak kalacaktı. Miloseviç ve en üst düzey askeri yardımcıları, BM insanlığa karşı suç mahkemesi tarafından suçlandıktan sonra bile hala iktidarın dizginlerini ellerinde tutuyordu. Avrupa yönetimlerine gelince, Kosova müdahalesi ortak bir diş politikanın herhangi bir biçimini elde etmek için ne kadar yol almaları gerektiğini açık bir şekilde gösterdi." (Hook \& Spanier, 2016).

Hook ve John'un değindiği gibi Avrupa Birliği'nin hem Yugoslavya sorunun başında hem de sonrasındaki yetersizliği ABD'yi yeniden Avrupa sorunlarına müdahale etmeye mecbur bırakmıştı. Çünkü ortaya çıkan güç boşluğunu Miloseviç gibi liderlerin doldurma ihtimali ABD'nin Soğuk Savaş sonrası tüm kazanımlarının alt üst edilmesi demekti. Bir de Balkanları tarihi nüfuz alanı olarak gören Rusya'nın kendini toparlaması ve Putin ile birlikte yeniden uluslararası arenada söz sahibi olmaya başlaması ABD'nin bölgedeki varlığını arttırıcı bir faktördür. ABD’nin bölgedeki çıkarlarını etkileyen faktörler genel olarak dört noktada toplanabilir: bölgesel istikrar, NATO'nun kriz ile baş etme yeterliliği, Avrupa'nın bir bütün olarak istikrarı ve Rusya ile ilişkiler (Uğrasız, 2004).

Kosova sorununun bir diğer önemi de bölgedeki Arnavut sorunu üzerine etkisidir. Yani Kosova'daki herhangi bir olay Makedonya'daki istikrarı etkileyebileceği gibi Avrupa güvenliğini ve istikrarını da tehlikeye atabilecektir (Kut, 2005). Yine, Balkanlarda ortaya çıkabilecek yeni bir çatışma riski de NATO'nun bölgedeki etkinliğinin ve krize müdahale yeteğinin sorgulanmasına yol açabilecektir. Zira NATO'nun Avrupa kıtasındaki bir soruna gerekli müdahale edememesi de ABD’nin Soğuk Savaş sonrası Avrupa güvenliğini sağlamayadığı ve tek süper güç olarak yeterli olmadığı eleştirilerini ortaya çıkaracaktır (Uğrasız, 2004). ABD'nin Bosna ve Kosova'da yaşamsal çıkarları olmayabilir. Ancak NATO’nun Avrupa Birliği'nin güvenliğini sağlamak zorunda olması sebebi ile ABD, Balkanlarda sorumluluk almak zorundadır. Aksi bir durumda Soğuk Savaş sonrası kazanımların birçoğu kaybedilebilecek ve gücünü yeniden toparlayan Rusya'nın bölgede yeniden nüfuz inşasına girişmesi mümkün olacaktır. ABD'de 'şahinler' olarak adlandırılan kanat, ABD'nin bölgedeki faaliyetlerinin arttırılması gerektiğini savunurken bu düşünceye karşı çıkan muhalifler de Balkanlardaki krizlerin temelde Avrupa'nın kendi sorunu olduğunu belirterek ABD'nin bu sorunun merkezinde yer almaması gerektiğini ve ABD'nin sadece kendi çıkarları için savaşması gerektiğini savunmaktadırlar (Uğrasız, 2004). Bu yaklaşım da ABD'nin I. Dünya Savaşı'ndan sonra kendi kabuğuna çekilmesini hatırlatmaktadır. Ancak, Waltz'un dediği gibi uluslarararası sistemde bir hegomanya olmadıkça anarşi ve kaos devam edecektir. Tam da bu nedenle ABD, oluşabilecek bir kaosun önüne geçebilmek ve NATO'nun sürekliliğini sağlamak adına Kosova sorunu ile yakından ilgilenmiştir.

NATO’nun sürekliliği ve dünyadaki etkinliği ABD için hayati önem taşımaktadır ki bu da ABD’nin Soğuk Savaş sonrası yeni bir çevreleme stratejisi planlamak istediğini göstermektedir. Ekonomik olarak bir deve dönüşen Çin'in bölgeyi etkisi altına alma ihtimali ve askeri açıdan hala bölgenin en güçlü ordusuna sahip olan Rusya'nın bölgedeki tarihsel nüfuzu ABD'nin bu yeni çevreleme stratejisinin en büyük nedenleri arasındadır. Bunun için de ABD, Kosova müdahalesi sonrası hemen ABD dışındaki en büyük askeri üssünü Bondsteel Camp'ı Kosova'da inşa etmiştir (Jovanović, 2018). Sonraki süreçte bölgedeki Amerikan etkisinin giderek arttı̆̆ görülmektedir. Özellikle Soğuk Savaş döneminde ABD karşıtı cephede yer alan ülkelerin birer birer NATO üyesi olması ve ABD'nin Kosova sonrası Bulgaristan ve Romanya'da da askeri üsler inşa etmesi Rusya tarafından tedirginlikle karşılanmış ve Rusya ABD'yi çevreleme politikasına devam ederek Rusya'yı etkisizleştirmeye çalışmakla suçlamıştır. Rusya'nın da Putin sonrası yeniden Balkanlara geri dönüş yaparak bölgedeki nüfuzunu korumaya çalıştığı görülmektedir (Lekic, 2018). Özelllikle Kosova'nın statüsü tartışmalarında bölgedeki Amerikan ve Rus rekabetinin yeniden canlandığı görülmektedir.

24 Mart 1999'daki NATO müdahalesi ardından 10 Haziran 1999'da Birleşmiş Milletler Güvenlik Konseyi, müdahale sonrası Kosova'nın geleceği ile ilgili 1244 nolu kararı aldı. Bu karara 
göre Birleşmiş Milletler Kosova Misyonu(UNMIK) kurulacak ve Kosova, UNMIK aracıllğı ile uluslararası toplum tarafından yönetilecekti. Yine bu karara göre, askeri komuta zinciri NATO'da olan bir koruma gücü de Kosova'da konuşlanacaktı. 1244 nolu karara göre Kosova, SirbistanKaradağ'ın bir parçasıdır (Wet, 2009). ${ }^{1}$ BMGK'den bu kararın çıkmasındaki en büyük etken Rambouillet görüşmelerine atıf yapmasıdır. Rambouillet görüşmelerine göre Kosova, özerklikten fazlasını ve bağımsızlıktan azını alacaktı. Ancak sonraki süreçte Kosova'nın bağımsızlık ilanı ve yönetimin UNMIK'ten $\mathrm{AB}$ gözetimindeki EULEX'e(Kosova Hukukun Üstünlüğü Misyonu) geçmesi Kosova'daki statü tartışmalarını yeniden başlatmıştır. Kosova'da statü tartışmaları yaşanırken ABD'yi en çok zorlayan konular, Kosova'nın nasıl istikrara kavuşturulacağı ve Kosova'nın siyasi statüsü olmuştur. Zira Kosova'nın 1244 sayılı karara göre Rusya'nın bölgedeki müttefiki Sırbistan'ın bir parçası olarak kalması, ABD'nin tüm çabasının boşuna gitmesi demek olabilirdi (Kalyoncu \& Yücel, 2019).

Asıl talepleri bağımsızlık olan Kosovalı Arnavutlar, bağımsızlığa giden yolda en büyük destekçilerinin $\mathrm{ABD}$ olduğuna inanırken, $\mathrm{BM}$ ve $\mathrm{AB}$ 'ye bu bağımsızlığa giden süreci geciktirdikleri için tepkililerdi. Rusya'nın bu bağımsızlığa net bir şekilde karşı çıkacağını açıklaması ABD'yi yeni dönemin yeni çevreleme stratejisi için daha da hırslandırmıştır (BBC Türkçe, 2008). Moskova yönetimi Putin'e geçtiği andan itibaren Ruslar her platformda Kosova'nın bağımsız olmasına izin vermeyeceklerini ve sorunun BMGK içerisinde 1244 sayılı karara göre çözülmesi gerektiğini vurgulamışlardır. ABD ise bu durumda BMGK'daki Rus vetosunu aşacak bir formül üretmek durumunda kalmıştır. Bu formüle göre $A B$ 'yi de sorunun Rusya ekseninden çıkması için ikna eden ABD, BM nezdinde Sırbistan'1 Arnavutların isteklerine cevap vermeleri için sıkıştıracak eğer Sırplar uzlaşmazlar ise bağımsızlığa yeşil 1 şı yakacak ve müttefiklerinden de bu bağımsızlı̆̆ desteklemesini isteyecektir. Planın ilk etabı BM'nin 24 Ekim 2005'teki Kosova'nın gelecek statüsü hakkındaki görüşmelerin başlatılması kararıdır. 20 Şubat 2006'da fiilen başlayan müzakerelerle BM'nin Kosova temsilcisi Marhi Ahtisaari, Kosova'nın statüsü üzerine bir rapor hazırlamıştır. Raporda Kosova için uluslararası denetimde bir bağımsızlık önerilmiştir. Rapor BMGK'da Rusya'nın engeline takılması üzerine $\mathrm{AB}, \mathrm{ABD}$ ve Rusya temsilcilerinin bulunduğu bir temas grubu kurulmuştur (Deutsche Welle, 2007). Temas grubunun da statü görüşmelerinde uzlaşaması üzerine Kosova, bir Pazar günü 17 Şubat 2008'de bağımsızlığını ilan etmiş ve böylece o gün çalışması mümkün olmayan BMGK'nin Rusya tarafından acil toplanmasının önüne geçilmiştir (Friedman, 2008).

ABD'nin Kosova'nın bağımsızlığını hemen tanıması ve ardından da diğer ülkelere tanımalarını tavsiye etmesi yeni dönemde BMGK'nın rolünün ne olacağı tartışmalarını doğurmuştur. Ancak ABD, askeri ve siyasi hegomanyasını kullanarak Rusya'nın Balkanlara güçlü bir şekilde dönmesinin önünü kesmiş ve bir anlamda onu yeniden çevrelemiştir. Ayrıca, ABD’nin bu desteği Arnavutlara vermesi önemlidir. Zira başta Arnavutluk ve Kosova'da olmak üzere Arnavutlar neredeyse bütün bölgede bulunmakta ve bulundukları ülkelerle sorunlar yaşamaktadırlar. Böylece ABD, Arnavutları yanına alarak, Makedonya, Sırbistan, Karadağ ve Yunanistan'da ileride oluşabilecek bir Arnavut sorununa karşı masaya oturma hakkını da elde etmiş̧ir. Kosova sorunu da ABD'nin bu politikasına göre Priştina ve Belgrad arasında bir mesele olmaktan çıkarılıp ABD ve Rusya arasında bir soruna dönüştürülmüştür. $\mathrm{Bu}$ da ABD'nin yeni çevreleme stratejisinin hedeflerinden biri olarak değerlendirilebilecektir. Miloseviç sonrası ilk bağımsız Sırbistan Başbakanı olan dönemin başbakanı Vojislav Kostunica da bu duruma dikkat çekerek şunları söylemektedir:

“Şimdi NATO'nun bombardıman sırasında Sirbistan'ın acımasızca yok edilmesinin tek bir amacı olduğu açıktır: Kosova eyaletini dünyanın ilk NATO devletine dönüştürmek. NATO'yu Kosova'daki nihai otorite olarak barındıran devasa Amerikan askeri üssü Bondsteel ve Ahtisaari

\footnotetext{
${ }^{1}$ Karadağ, 2006’da bağımsızlığını ilan ederek Sırbistan'dan ayrılmıştır.
} 
planının Ek 11'inin yasadışı inşası, Sirbistan'ın akllsızca harap olmasının ve 17 Şubat'ta bir NATO devletinin neden yasadışı ilan edildiğini ortaya koyuyor." (McLaughlin, 2008).

ABD'nin Kosova sorununa yaklaşımı üzerine birçok farklı değerlendirme yapılmaktadır. Ancak yapılan değerlendirmelerin birçoğundaki ortak kanı ABD'nin Sovyetler sonrası tekrar güçlenen Rusya'nın Avrupa'da yeniden nüfuz sahibi olmasını engellemek istediğidir. Örneğin, Ted G. Carpenter bir makalesinde Sovyetler sonrası Amerikan-Rus ilişkilerini zehirleyen şeyin Kosova olduğunu belirtmektedir. Yani, ABD'nin Kosova hamlesi uluslararası ilişkilerde yeni bir kaos döneminin kapısını açmış ve sonrasında ABD'den gelecek Ukrayna ve Gürcistan hamlelerine karşı Rusya da Kosova reaksiyonu ile tepki vermiştir (Carpenter, 2017). ABD’nin Kosova'ya müdahalesinin temelinde NATO aracıllı̆g ile Soğuk Savaş dönemindeki konumunu koruma ve Rusya'y1 Balkanlarda ve Kafkasya'da çevreleme hedefi olduğu söylenebilecektir. Kosova operasyonundan sonra Gürcistan'daki ‘Gül Devrimi' de bu 'yeni çevreleme' konseptinin bir parças1 olarak değerlendirilebilecektir. Putin liderliğindeki Rusya'nın Gürcistan ve Ukrayna müdahaleleri de ABD'nin yeni çevreleme konseptine karşı Rus reaksiyonu olarak değerlendirilebilecektir. Arap Baharı sonrası Libya ve Suriye'de sona ermeyen savaş da bir anlamda Rusya'nın ABD'nin bu siyasetine karş1 verdiği tepki olarak düşünülmektedir (Frolovskiy \& Semenov, 2020).

\section{Sonuç}

Soğuk Savaşın ardından, uluslararası siyasetteki güç dengesi Sovyetlerin dağılması ile birlikte ABD'nin tek lider olarak kaldığı tek kutuplu bir yapıya dönüşmüştü. Tarihin sonu tezi tartışması sürerken birçok uluslararası ilişkiler uzmanı, Soğuk Savaş sonrası için daha önce yaptıkları tahminlerde tek kutuplu sistemin bir takım sorunları beraberinde getireceğine inanıyordu. Örneğin Rober Gilpin (1981) ve Kenneth Waltz(1959), bu durumun tek güç olarak kalan devletin zayıf devletlerden menfaat sağlamaya çalışacağını, tek güçlü egemen olmanın maliyetinin yüksek olduğunu ve eninde sonunda bu durumun tek güç olan devleti zayıflatacağını ve tek gücün hegomanyasından rahatsız olan diğer güçlü devletlerin onu yıpratmaya çalışacağını söylerler (Gilpin, 1981; Waltz, 1959). Tek güç olarak kalan ABD'nin kendinden daha zayıf devletlerden menfaat sağlama tartışmalarının özellikle ticaret savaşları ve amborgolar kartı ile sıkça kullanıldığı görülmektedir. ABD'nin tek güç olmasının maliyeti tartışmaları da her NATO toplantısında ABD'nin diğer müttefiklerden ekonomik olarak daha çok sorumluluk almalarını istemesi üzerinden değerlendirilebilecektir. Son olarak da diğer güçlü devletlerin ABD'yi yıpratmaya çalışması tartışması da Çin'in ekonomik ve Rusya'nın da siyasi ve askeri manevraları ile değerlendirilebilir. Ayrıca, AB'nin giderek ABD'den siyaset olarak faklılaşması da tek güçlü bir sistemin krizi olarak yorumlanabilecektir.

ABD’yi Soğuk Savaş sonrası etkileyen en önemli kriz hiç kuşkusuz ki 11 Eylül saldırılarıdır. ABD’nin ‘teröre karşı savaş’ parolası ile girdiği mücadele dünya siyasetini yeniden şekillendirmiştir. 11 Eylül ile birlikte 'medeniyetler çatışması tezi' yeniden tartışılsa da sonraki süreç tek kutuplu dünyanın sancılarını göstermektedir. Özellikle Rusya ve Çin'in 21. yüzyılda ekonomik, siyasi ve askeri olarak yükselişi tek kutuplu sistemin değişim geçirdiğini göstermektedir. Kosova krizi, krize müdahale ve sonrasında yaşananlar sistemdeki bu değişime verilen tepkiler olarak yorumlanmalıdır. Aslında Amerikan dış politikası bütün bu yaşananlara kendine özgü bir tarz ile cevap vermeye devam ediyor. Kosova sorunu örneğinde ABD, Soğuk Savaşı kazanmış bir ülke olarak rahat davranmamış ve liderlik üstlenerek sorunu kendi yöntemleri ile çözme yoluna gitmiştir. Zira ABD, Saddam Hüseyin'in Kuveyt müdahalesi örneğinde olduğu gibi soruna geçici bir sorun üreterek maliyeti yüksek yeni bir Irak sorununa kavuşmak istemedi. Kosova'da müdahalesiz geçici bir çözüm, Sırbistan'da Miloseviç yönetimini güçlendirebilirdi. Miloseviç önderliğindeki Sırbistan'ın da yeniden güçlenen Rusya ile bir ittifaka giderek bölgedeki krizi yeniden derinleştirme ihtimali, ABD'yi Rusya'nın deyimi ile 'oldu bitti' politikasına yöneltmiştir. Sonrasında Kosova'da kurulan devasa Amerikan askeri üssü ile $\mathrm{ABD}$, arka bahçesinde sorun istemeyen $\mathrm{AB}$ 'yi de yanına alarak Sırbistan'1 yumuşamaya zorlamış ve Doğu Avrupa'da Belarus ve Moldova haricindeki tüm ülkeleri 
NATO şemsiyesi altına almıştır. Bu durum da uluslararası sistemin yeniden bir güç dengesi oluşturduğunu ve tek kutupluluğun dönüştüğünü göstermektedir. ABD’nin bu yeni duruma karş1 tepkisi yeni bir çevreleme politikası ile Rusya ve Çin'i sınırlamaya çalışmak olmuştur.

Sonuç olarak, Soğuk Savaş sonrası uluslararası sistemdeki yeni güç dengesinin nasıl oluşacağı tartışmaları hala bitmiş değildir. Küreselleşme ile ulus devletin sona ereceği iddiası birçok kez sınanmıştır. Önce Yugoslavya'nın birçok yeni ulus devlete dönüşmesi, sonrasında da 2008 ekonomik krizi ve bugün yaşanan korona virüs salgınında yaşananlar, uluslararası sistemde tek ve biricik olan aktörün ulus devlet olduğunu göstermiştir. Mevcut uluslararası sistem içerisinde anarşinin yerine küresel bir uzlaşının oluşturulabileceği hala ütopik bir hayal olarak görünmektedir. Çalışmanın genel bir değerlendirilmesi yapılacak olursa, Kosova örneği üzerinden ABD'nin Rusya'ya karşı yeni bir çevreleme politikası ile güç mücadelesi ve rekabet konseptine geçtiği görülmektedir. Yine Kosova krizi, ABD’nin Soğuk Savaş'ta rakiplerine karşı uyguladığı çevreleme politikasının Soğuk Savaş sonrasında da süreklilik gösterdiğine iyi bir örnektir.

\section{Kaynakça}

BBC Türkçe. (2008, Şubat 2008). Rusya'dan bir Kosova uyarısı daha. Nisan 2, 2020 tarihinde BBC Türkçe:

http://www.bbc.co.uk/turkish/europe/story/2008/02/printable/080215_serbia_russia_un.sht $\mathrm{ml}$

Carpenter, T. G. (2017, Mayıs 19). How Kosovo Poisoned America's Relationship with Russia. Nisan 2, 2020 tarihinde National Interest: https://nationalinterest.org/feature/how-kosovopoisoned-americas-relationship-russia-20755

Deutsche Welle. (2007, Temmuz 21). Kosova'nın bağımsızlı̆̆ çıkmazda. Nisan 2, 2020 tarihinde Deutsche Welle: https://p.dw.com/p/BKT3

Donnely, J. (2012). Realizm. S. Burchill, \& A. Linklater içinde, Uluslararası İlişkiler Teorileri (A. Aslan, \& M. A. Ağcan, Çev., s. 49-80). Küre Yayınları.

Fox, J. (2005). Paradigm Lost: Huntington's Unfulfilled Clash of Civilizations Prediction into the 21st Century. International Politics(42), 428-457. doi:https://doi.org/10.1057/palgrave.ip.8800116

Friedman, G. (2008, Şubat 20). Kosovar Independence and the Russian Reaction. Nisan 2, 2020 tarihinde Stratfor: https://worldview.stratfor.com/article/kosovar-independence-andrussian-reaction

Frolovskiy, D., \& Semenov, K. (2020, Ocak 21). For Russia, Libya and Idlib are now part of the same gamble. Nisan 3, 2020 tarihinde Middle East Institute: https://www.mei.edu/publications/russia-libya-and-idlib-are-now-part-same-gamble

Fukuyama, F. (1989). The End of History? The National Interest, 3-18.

Gilpin, R. (1981). War and Change in World Politics. Cambridge.

Herring, E. (2000). rom Rambouillet to the Kosovo accords: NATO'S war against Serbia and its aftermath. The International Journal of Human Rights, 4(3-4), 224-245. doi:10.1080/13642980008406901

Hobbes, T. (2019). Leviathan. (S. Lim, Çev.) Yapı Kredi Yayınları.

Hook, S. W., \& Spanier, J. (2016). Amerikan Dış Politikası. (Ö. Zihnioğlu, Çev.) İnkılap Kitabevi.

Huntington, S. (1996). The Clash of Civizilations and Remarking of World Order. Simon\&Schuster. 
Jovanović, Ž. (2018, Ocak 13). Close Camp Bondsteel: America's Military Base in Kosovo and Metohija. Nisan 1, 2020 tarihinde Global Research: https://www.globalresearch.ca/closecamp-bondsteel-americas-military-base-in-kosovo-and-metohija/5625962

Kalyoncu, Ş., \& Yücel, G. (2019). Soğuk Savaş Sonrası Kosova'da Yükselen Etnik Milliyetçilik Ve Balkan Güvenliği. Akademik Hassasiyetler, 6(12), 251-267.

Kissenger, H. A. (2011, Kasim 10). The Age of Kennan. Mart 30, 2020 tarihinde The New York Times: https://www.nytimes.com/2011/11/13/books/review/george-f-kennan-an-americanlife-by-john-lewis-gaddis-book-review.html

Klein, H. S. (1999). The Atlantic Slave Trade. Cambridge: Cambridge University Press.

Kut, Ş. (2005). Balkanlar'da Kimlik ve Egemenlik. İstanbul Bilgi Üniversitesi Yayınları.

Lekic, S. (2018, May1s 1). Russia's influence campaign in the Balkans has US military leaders on edge. Nisan 1, 2020 tarihinde STARS AND STRIPES: $\mathrm{https}$ ://www.stripes.com/news/russia-s-influence-campaign-in-the-balkans-has-us-militaryleaders-on-edge-1.524881

McLaughlin, D. (2008, Mart 25). Serbs say Kosovo is illegal 'Nato state'. Nisan 2, 2020 tarihinde The Irish Times: https://www.irishtimes.com/news/serbs-say-kosovo-is-illegal-nato-state1.906555

Özcan, G. (2019, Kasım). Çevreleme Politikası. Güvenlik Yazıları Serisi(41), s. 1-8. doi:10.13140/RG.2.2.28146.66247

The Guardian. (2005, Mart 19). George Kennan. The Guardian: https://www.theguardian.com/news/2005/mar/19/guardianobituaries.usa

The Secretariat of The Federal Assembly Information Service. (1974). The Constitution of The Socialist Federal Republic of Yugoslavia. (M. Pavicic, Çev.) Ljubljana: Dopisna Delavska Univerza. Mart 30, 2020 tarihinde https://www.worldstatesmen.org/YugoslaviaConstitution1974.pdf

U.S Embassy Ankara. (2007, Mayıs). Marshall Planı: Avrupanın Yeniden Yapılandırılması. Mart 30, 2020 tarihinde U.S Embassy Ankara: http://www.usembankara.org.tr/The_Marshall_Plan/index.html

Uğrasız, B. (2004). ABD'nin Soğuk Savaş Sonrası Balkan Politikası. Dokuz Eylül Üniversitesi Sosyal Bilimler Enstitüsü Dergisi, 6(1), 295-303.

Vrkic, N. (2015). The unfinished trial of Slobodan Milošević: Justice lost, history told. Nisan 1, 2020 tarihinde UvA-DARE (Digital Academic Repository): https://pure.uva.nl/ws/files/2517864/164012_04.pdf

Waltz, K. (1959). Man, the State, and War. New York: Columbia University.

Waltz, K. N. (2015). Uluslararası Politika Teorisi. (O. S. Binatlı, Çev.) Ankara: Phoenix Yayınevi.

Wet, E. d. (2009). The Governance of Kosovo: Security Council Resolution 1244 and the Establishment and Functioning of eulex. American Journal of International Law, 103(1), 8396. doi:https://doi.org/10.2307/20456723 